\title{
Feasibility study of technology-enabled prevention intervention for children and families
}

\author{
Nikki Theofanopoulou ${ }^{1}$, Katherine Isbister ${ }^{2}$, Julian Childs $^{1}$, and Petr Slovak ${ }^{3}$ \\ ${ }^{1}$ Evidence Based Practice Unit, University College London and Anna Freud National Centre for Children and \\ Families, London, UK \\ ${ }^{2}$ University of California Santa Cruz, Department of Computational Media, Santa Cruz, USA \\ ${ }^{3}$ King's College London, Department of Informatics, London, UK
}

\begin{abstract}
Background: A common challenge within psychiatry and prevention science more broadly is the lack of effective, engaging, and scale-able mechanisms to deliver psycho-social interventions for children, especially beyond in-person therapeutic or school-based contexts. Although digital technology has the potential to address these issues, existing research on technologyenabled interventions for families remains limited.

Objective: The aim of this pilot study was to examine the feasibility of in-situ deployments of a low-cost, bespoke prototype, which has been designed to support children's in-the-moment emotion regulation efforts. This prototype instantiates a novel intervention model that aims to address the existing limitations by delivering the intervention through an interactive object (a 'smart toy') sent home with the child, without any prior training necessary for either the child or their carer. This pilot study examined (i) the engagement and acceptability of the device in the homes during 1 week deployments; and (ii) qualitative indicators of emotion regulation effects, as reported by parents and children.

Methods: In this qualitative study, ten families (altogether 11 children aged 6-10 years) were recruited from three underprivileged communities in the UK. The RA visited participants in their homes to give children the 'smart toy' and conduct a semi-structured interview with at least one parent from each family. Children were given the prototype, a discovery book, and a simple digital camera to keep at home for 7-8 days, after which we interviewed each child and their parent about their experience. Thematic analysis guided the identification and organisation of common themes and patterns across the dataset.In addition, the prototypes automatically logged every interaction with the toy throughout the week-long deployments.

Results: Across all 10 families, parents and children reported that the 'smart toy' was incorporated into children's emotion regulation practices and engaged with naturally in moments children wanted to relax or calm down. Data suggests that children interacted with the toy throughout the duration of the deployment, found the experience enjoyable, and all requested to keep the toy longer. Child emotional connection to the toy-caring for its 'well-being'-appears to have driven this strong engagement. Parents reported satisfaction with and acceptability of the toy.

Conclusions: This is the first known study investigation of the use of object-enabled intervention delivery to support emotion regulation in-situ. The strong engagement and qualitative indications of effects are promising - children were able to use the prototype without any training and incorporated it into their self-regulation practice during daily challenges. Future work is needed to extend this indicative data with efficacy studies examining the psychological efficacy of the proposed intervention. More broadly, our findings suggest the potential of technology-enabled shift in how prevention interventions are designed and delivered: empowering children and parents through 'child-led, situated interventions', where participants learn through actionable support directly within family life, as opposed to didactic in-person workshops and a subsequent skills application.
\end{abstract}

\section{Introduction}

Mental health conditions are the main contributor to the substantial increase in childhood disability in the last decade ${ }^{1}$, with most having their onset in childhood or adolescence ${ }^{2,3}$. Recent estimates suggest a $10 \%$ prevalence of mental disorders in children and adolescents in Great Britain ${ }^{4}$ and $12 \%$ in Europe ${ }^{5}$, while approximately one in every $4-5$ youth in the U.S. meets criteria for a mental disorder with severe impairment across their lifetime ${ }^{6,7}$. This realisation is fuelling calls for interventions in childhood to avert the development of long-term disability ${ }^{8-10}$. Research in Prevention Science showcases the feasibility of such interventions in child populations: these programs develop key cognitive and emotional protective factors-such as emotion regulation or coping strategies-which in turn can reduce the incidence of mental health disorders in later life ${ }^{11-17}$. However, similarly to therapeutic settings, existing prevention programs rely predominantly on in-person training. As a result, these interventions struggle with the challenges of cost, reach, and intervention fidelity ${ }^{18-22}$.

While existing programs are relatively successful in targeting children within the 'captive audience' context of schools ( $\mathrm{se}^{21,23-25}$ for reviews), a principal challenge remains in extending this support into the day-to-day contexts in which protective 
competencies are applied, practised, and developed ${ }^{22}$. The current model relies on parents to deliver such at-home interventions and requires extensive training to do effectively: For example, a shortened version of the Incredible Years program ${ }^{26,27}$ still $^{2}$ required 12-24 weeks of parent training in groups of 6-10 parents for 2.5 hours, once a week. Other programs, such as the seminal Perry Pre-school program, were even more intensive, comprising a 2-year program of 2.5 hours of interactive academic instruction daily for children at school, coupled with 1.5 -hour weekly home visits by trained staff ${ }^{28}$. Such approaches experience low enrolment rates and the lack of continued engagement with interventions beyond formally delivery classroom context is also a common limitation ${ }^{18-20}$. These difficulties in bridging the formal school and informal home contexts are crucial in Prevention Science: family interactions are a strong mediating factor for developing resilience and impact core socio-emotional competencies especially for younger children ${ }^{29-33}$; moreover, lack of consistency of at-home and at-school support diminishes the effects of prevention programs ${ }^{22,34}$.

New delivery mechanisms and intervention approaches are sorely needed to address these issues (cf., ${ }^{8}$ ). Digital mental health interventions are increasingly seen as having the potential to deliver on these aims, revolutionising when, how, where, to whom interventions can be delivered ${ }^{10,35-37}$. While the interest in technology-enabled mental health continues to soar-especially in the context of treatment for adult populations - a consistent set of challenges has however emerged around ensuring uptake and long-term engagement of online interventions (see e.g., ${ }^{10,38}$ ). Reliance on didactic and information delivery models, limited use of user-centred design, and lack of immediately perceived benefits leading to low motivation are commonly cited reasons ${ }^{39-41}$. These difficulties are likely to be exacerbated within prevention interventions for children, but surprisingly little research has investigated it empirically ${ }^{42,43}$. As such, it is not clear if/how technology could be used to facilitate transfer of such learning from school into families; or to enable new types of interventions that would empower parents and children to further develop protective competencies independently of formal training programs.

\section{Present research}

This work investigates a proof-of-concept prototype of a newly proposed intervention delivery mechanism within the context of (i) universal prevention programs ${ }^{25}$ for children aged 6-10 and their families; and (ii) emotional regulation (ER) as a specific instance of a psychological protective factor. We chose emotion regulation as it is a fundamental life skill, with effects on life outcomes comparable in size to those of IQ or family social status ${ }^{44,45}$. Research shows that these effects are wide-reaching: if ER is poorly developed, it leads to increased incidence of both internalising and externalising mental health disorders ${ }^{4-49}$, and is associated with societal problems such as criminal behaviour ${ }^{50}$, low personal well-being ${ }^{44}$, and academic under-achievement ${ }^{51}$. Moreover, existing intervention research shows that emotion regulation is difficult to develop without detailed in-situ guidance and support ${ }^{26,52-54}$; and parenting strategies play a key role in shaping child emotional coping and regulatory skills ${ }^{55-63}$.

The data reported here builds on an iterative user-centred design process, which led to the development of a bespoke intervention prototype described in the next section. Within the two-year-long development phase (reported in full elsewhere ${ }^{64}$ ), we worked with children, parents and Prevention Science experts to co-design a proof-of-concept technology platform to support children in developing emotion-regulation skills. Theoretically, the intervention is grounded both in basic models of emotion regulation ${ }^{65}$, as well as close collaboration with developers of evidence-based interventions (Second Step); while also deeply involving children and families in co-design to ensure the intervention fits into their daily lives (cf., ${ }^{39,40,66}$ ). In effect, the designed prototype attempts to fuse the understanding of evidence-based methods from Prevention Science (what works), Human-Computer Interaction (what is technically feasible); as well as insights into the everyday practices of families within the designed for social context (what people actually do). This iterative design process has led to a novel intervention model, whereby the intervention is delivered through an interactive object ('smart toy') sent home with the child, without any prior training necessary for either the child or their carer (see next section for design details and logic model).

\section{Feasibility study aims}

The aim of this qualitative study was to provide an initial validation of the feasibility of core fundamental principles underpinning the proposed intervention as instantiated within the proof-of-concept prototype (cf., ${ }^{67}$ ). Specifically, the intervention model assumes (i) that children will be naturally compelled to keep interacting with the intervention without external guidance; (ii) that it will become incorporated into their everyday emotion regulatory practices, even without any formal training; and (iii) that the intervention will be perceived as acceptable to parents. Given the novel nature of the proposed delivery mechanisms, it is crucial to test whether these principles are fulfilled by the current prototype, before more expansive investigations take place.

Data from exploratory deployments reported in ${ }^{68}$ are promising; however, these are limited by short post-hoc interviews with children, no information from parents, no objective log data, and only very short deployment times (median 3 days). This study builds on these preliminary findings, using a range of data-collection methods (pre-/post- interviews with parents and children, log data analysis, child photo diaries) to investigate:

(i) the engagement and acceptability of the device in the homes during 1 week deployments; and 
(ii) the subjective indicators of effects on emotion regulatory practices (whether positive or negative), as reported on parents and children.

\section{Intervention design and logic}

The prototype takes the form of a hand-crafted plush toy (see Fig 1-a), which was designed to travel home with the child from school and support in-the-moment soothing. The toy is introduced to the child as an 'anxious creature that needs kind attention from humans', such as soft stroking and hugging. Embedded electronics enable the prototype to produce vibration patterns that simulate a heartbeat (ranging from frantic to slow and steady). When picked up, the toy elicits a frantic heartbeat that slows down if the child uses calm stroking movements, as registered by the embedded sensors. If the toy is 'soothed' for long enough, the prototype transitions into a purring vibration indicating a very satisfied state.

The proposed logic model underlying the intervention is assumed to operate on three levels building on each other: (i) the first level pertains to directly providing in-the-moment soothing support to children in naturally occurring emotional moments when they would attempt to calm down; (ii) the second is concerned with mechanisms that facilitate children's longer-term engagement with the intervention, providing meaning and motivation for ongoing use; while (iii) the third is assumed to emerge from repeated experience of soothing interactions over time, leading to a shift in children's emotion regulation practices and implicit beliefs about emotion. The present study aimed to provide pilot indicative data pertaining to levels \#1 and \#2.

Level 1 - In-the-moment support The prototype's physical and interaction design was aimed to tap into a number of known regulatory factors, grounded theoretically in Gross' extended process model of emotion regulation ${ }^{65}$. This model categorises emotion regulation processes depending on the point in the emotion-generative process at which they operate. We designed the prototype interaction with the aim to impact two separate stages: the attentional deployment stage, by shifting children's attention from the emotion-eliciting situation towards interacting with the toy; and the response modulation stage, by facilitating down-regulation through pleasant tactile interaction. Due to the temporal dynamic and circular nature of the emotion regulation process over time, the two stages are expected to be functionally linked and support each other in nudging the child towards reduction of negative emotions at each instance of the regulatory circle. Such sequenced strategies have been previously shown to be effective (cf., ${ }^{69}$ ) and are commonly observed in practice ${ }^{65,70}$. The specific research grounding and design choices supporting the individual mechanisms were as follows:

- Attention deployment: Research on emotion regulation choice has shown that in high-intensity situations, individuals prefer diverting their attention from emotional stimuli, possibly because disengaging attention early on provides shortterm relief with minimal effort by successfully blocking emotional information at an early processing stage before it gathers force ${ }^{71-73}$. We hypothesized that the interaction with the prototype could support such attentional re-deployment: by focusing on the 'toy' and its interactive responses to their manipulation, children would distract themselves from the emotional situation they were encountering. Shifting and maintaining attention away from the negative emotional triggers can possibly disrupt cognitive elaboration on the negative events (i.e., rumination) and allow the negative emotions to subside ${ }^{74}$. The framing of 'taking care' of the pet was assumed to provide further motivation and meaning for the child-toy interaction $\left(\mathrm{see}^{75}\right)$, thus acting as a secondary, cognitive mechanism facilitating attentional deployment.

- Response modulation: Research across a range of domains suggests that tactile stimulation may be one of the adaptive response modulation strategies in buffering stress responses: this mechanism is assumed to underpin the emotion regulatory effects of human-animal interaction ( $\mathrm{cf}^{76}$ for a review), play a role in effects of 'social touch" ${ }^{77-79}$, and the soothing effects of animal-like robots ${ }^{80,81}$. Based on this literature, we hypothesised that the interaction with the prototype could also tap into the response modulation stage by affecting the child's physiological emotional response.

Level 2 - Ongoing engagement The second level then directly builds on the positive subjective experience of in-the-moment soothing to facilitate long-term engagement with the toy through the associated narrative. The framing of the toy as an 'anxious creature in need of assistance' is the hypothesised key driver: we assume that this framing will not only support convey the benefits resulting from extrinsic emotion regulation ${ }^{77,82,83}$, but also facilitate the creation of a sense of relationship and responsibility for the 'well-being' of the creature, similar to the long-term engagement seen with child-oriented robots (e.g., $\left.{ }^{75}\right)$ or products such as Tamagotchi ${ }^{84-86}$. If the design and associated narrative are successful in creating an emotional attachment to the toy, we expect that children will treat it as a being with thoughts and feelings ${ }^{87}$, which then provides another layer of meaning to their interactions, facilitates the incorporation of the child-prototype interactions throughout everyday situations, and further motivates sustained engagement.

Level 3 - Shift in emotion regulation practices and implicit beliefs about emotion Finally, we envision that repeated interactions with the toy will result in the establishment of more adaptive emotion regulation patterns and shift children's 

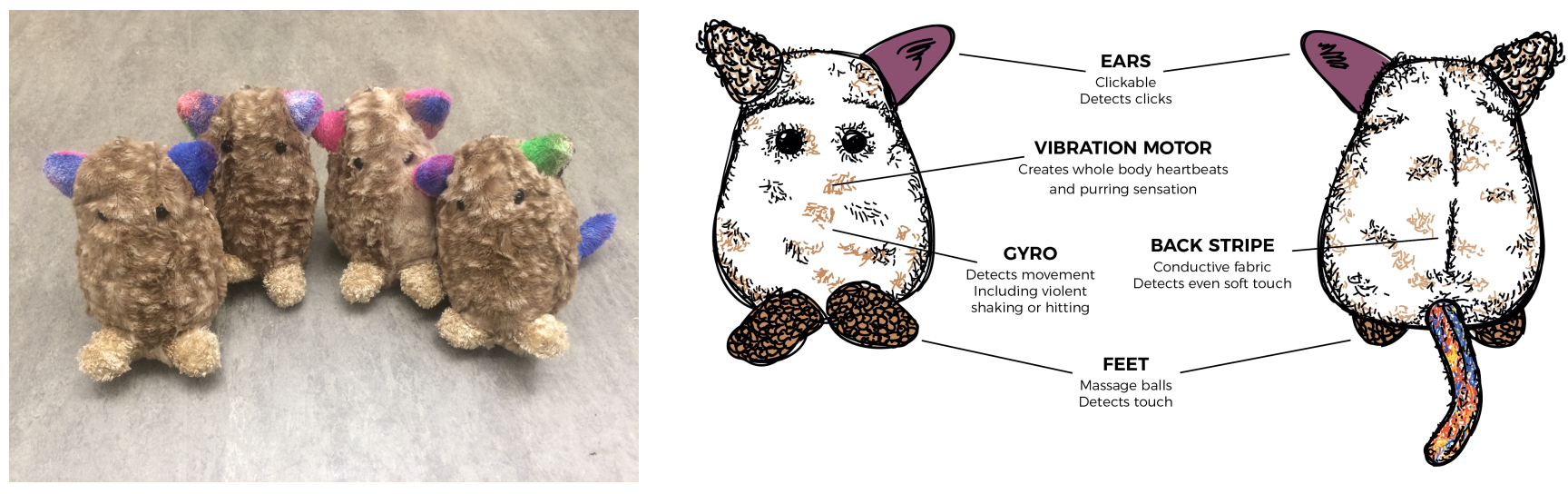

Figure 1. (a) The physical prototype; (b) Overview of the prototype's interactive components

implicit beliefs about the controllability of emotion ${ }^{70,88}$. Specifically, we hypothesise that the repeated experience of inthe-moment soothing will influence children's implicit beliefs about emotion over time, leading them to evaluate emotions as more controllable (as they are consistently regulating these with the help of the toy), and therefore themselves as more equipped to cope. Beliefs about the controllability of emotion are considered a prime target for intervention as they have implications for emotion regulation ${ }^{89-93}$. They are of critical importance both for acute (e.g., emotional experiences), and more chronic, cumulative outcomes (e.g., well-being): numerous studies have found that the belief that emotions are uncontrollable is correlated with worse psychological health ${ }^{94-96}$, and predictive of future depressive symptoms ${ }^{89,97}$. Moreover, enabling children to assume the role of caretaker and 'regulator' for someone else (through the attribution of emotions to the toy) might provide them with opportunities to practise and enhance their emotion regulation skills, which they can then apply to future situations where they themselves need to calm down. This is consistent with prior research, suggesting that helping others regulate their emotional reactions can improve one's own regulatory skills and emotional well-being ${ }^{77,83}$. As these effects are expected to arise only through on-going long-term interactions and thus rely strongly on appropriation in-situ, we did not expect to see any indicative data for these proposed mechanisms within this pilot study.

\section{Method}

The goals of this early feasibility study were to investigate the engagement and acceptability of the device in the homes during 1 week deployments with children aged 6 to 10 years and their families; and also subjective indicators of effects on emotion-regulatory practices (whether positive or negative), as reported on by the parents and children. Together, the aim was to collect indicative qualitative data pertaining to level $1 \& 2$ of the underlying logic model: we were interested to see if children will find the individual interactions comforting, whether they will sustain engagement over the week periods (and what role any emerging 'relationship' with the toy might play here), and whether the toy will become embedded into their everyday activities, including being explicitly used for emotion regulation.

\section{Study Design}

As we were interested in studying natural appropriation in situ, children were given a prototype, a 'discovery book' that presented the simple narrative and suggested playful activities, and a simple digital camera to keep at home for 7-8 days. We gathered data through a number of channels: (1) the main source were semi-structured interviews with parents and children prior to and right after the deployment; (2) any photos children took during the deployment, which also served as 'ticket to talk' about their experiences during the week; and (3) automatically collected logs by the prototype, which recorded all touch interactions throughout the weekly deployment.

The discovery book contained some information about the 'creature's' background and various activities the child could fill in on their own or with the help of their parents, such as 'photo challenges' around the toy, and an 'emoji diary' where they child could use emoji stickers to keep track of how they and their 'creature' were feeling on each day of the deployment. In designing the discovery book and activities, our aim was to facilitate children's engagement with the toy in a playful manner, as well as complement the interview data with a richer understanding of how families experienced having the toy at home. As such, the discovery book was as much a research tool, as a part of the intervention (implicitly providing the narrative and suggested activities).

The study was funded by a personal fellowship and University College London (UCL), and received ethical approval from UCL's Ethics Committee (3923/005). 


\section{Recruitment}

The prototypes and accompanying materials were deployed in waves to families of 11 children ( 3 girls, 8 boys, aged 6-10) from August to November 2018. One family experienced a malfunctioning prototype and has been removed from the analysis. Participants were recruited from three underprivileged communities in the UK through a range of methods, including online advertisements, in-person recruiting in two schools who had served as recruitment sites for previous phases of the project, and snowball sampling.

\section{Procedure}

The RA visited families who had orally agreed to take part to obtain consent from parents, and assent from children, conduct a semi-structured interview with at least one parent and give children the toy, discovery book, and a simple digital camera to keep at home for 7-8 days (one deployment was extended for a day due to a technical failure, and two more for scheduling reasons). The first semi-structured interview with parents focused on families' existing emotion-regulatory practices, perceived challenges to emotion regulation, and parents' expectations from the week-long deployment. The interviews sessions (approx. 1 hour) were conducted in person in participants' homes. After 3 or 4 days, the RA visited families again to change the toy's battery. On the last day of the deployment, the RA visited the families to pick up the toy and materials and interview each child and at least one of their parents individually. Engagement with the toy was tracked automatically by the toy throughout the deployment, by registering and logging every interaction with a time-stamp.

The semi-structured interview conducted at the end of the deployment included questions designed to elicit participants' views and experiences of using the toy, as well as their expectations of longer term outcomes if they were to keep it for longer. During the interviews, the photos children took and the completed activities in their discovery books were used as prompts to ask families about children's engagement with the toy. The interview sessions (approx. 1 hour for the parent interview and 30 minutes for the child interview) were conducted in person in participants' homes when the RA visited the families to collect the toy and accompanying materials. Families were offered $£ 50$ compensation for their time.

\section{Data Analysis}

Analysis of interview data As the existing emotion-regulatory practices reported by families during the pre-deployment interviews were similar to those described in prior work ${ }^{64}$, and post-deployment interview data were rich enough to answer the research questions, we decided to focus the analysis predominantly on the post-deployment interviews. Interview recordings were transcribed verbatim by the first author and an independent RA, and then included into an inductive thematic analysis. Following Braun and Clarke's 6-step recursive process of thematic analysis ${ }^{98}$, the transcripts were checked against audio recordings for accuracy, and then read and re-read by the first author to ensure familiarization with the data. Initial codes were then generated across the data set. As new ideas emerged and codes were refined while working through the transcripts, previously coded transcripts were revisited to ensure that the codes still applied. Once code application was complete, resulting in 603 coded passages and 2226 code applications, different codes were sorted into potential themes by the first and fourth author, which were then refined to generate an initial thematic map of the analysis. The refinement of the thematic map involved several iterations, until authors agreed that the final themes and sub-themes told a coherent story about the data. To protect anonymity, participants are referred to by using $\mathrm{P}$ for parents and $\mathrm{C}$ for children, followed by a participant number.

Analysis of log data The prototypes logged every interaction throughout the deployment. Due to Arduino limitations, the sampling rate differed depending on the quickness of the 'heartbeat' as the sensors were polled in between every two beats: the sampling rate was about $2 \mathrm{~Hz}$ in the 'anxious' state, and about $0.7 \mathrm{~Hz}$ in the 'happy' state. The first author kept a detailed $\log$ about the time when the toys were introduced and removed from the families. The resulting log files ( $\sim 4.5$ million lines) were then processed in R, post-deployment. It is important to note here that as the data only represents activation of the toy's sensors (on its back, ears, fee t, or gyro), interpretation is limited: for instance, if the toy was moved from one place to another, or placed in a bag to be transported, a sensor could be unintentionally activated by the pressure. To partially mitigate such 'accidental activations', we have removed lines with less than 20 separate sensor signals from analysis.

\section{Results}

The study included 11 children from 10 families as a pair of siblings received one toy each during the same week (female children $\mathrm{N}=3$; female parents $\mathrm{N}=11$; mean age children 7.1 years [SD $=1.22$, range 6-10]; mean age parents 37 years [SD $=5.36$, range 28-44]. One additional family had a malfunctioning prototype and has been removed from the main analysis. Figure 2 includes individual information for age, gender and other deployment related information for each of the children. We had no attrition; all participants finished all phases of the study. 


\begin{tabular}{|c|c|c|c|}
\hline Child & Age & Gender & Toy's name and gender \\
\hline C1 & 6 years old & Male & Jade/Pipsqueak (Female) \\
\hline C2 & 6 years old & Female & Coco (Male) \\
\hline C3 & 6 years old & Female & Winter (Female) \\
\hline C4 & 6 years old & Male & Mr. Scared (Male) \\
\hline C5 & 7 years old & Male & Frankie (Male) \\
\hline C6 & 7 years old & Male & Creature (Female) \\
\hline C7 & 8 years old & Female & Rainbow (Female) \\
\hline C8a & 7 years old & Male & Wootie (Female) \\
\hline C8b & 10 years old & Male & Missy (Female) \\
\hline C9 & 7 years old & Male & Happy (Male) \\
\hline C10 & 8 years old & Male & Buddy (Male) \\
\hline
\end{tabular}

Figure 2. Overview of child demographics and the labels they associated with the prototype

\section{Qualitative results \\ Engagement and appropriation}

In describing their experiences over the week, all children (11/11) outlined how the toy became included in their everyday routines, whether these were cuddling and stroking the toy when watching TV, playing with their other toys, or going to bed; or more active play such as role play scenarios (see Figure 3 for example photos taken by children). For most children (10/11), their parents or themselves reported that they wanted to carry the "creature with them wherever they went" and were keen to show it to family and friends.

"They were like instantly connected. Everywhere she went, she'd hug him, she spoke to her dad about Coco, to her grandmother, to her cousins. Very proud." [P2]

"Creature goes wherever [my child] goes... Creature comes to bed, Creature sits with us at dinner, Creature watches his tablet, Creature does just everything does. Even if we go shopping, we come to mum, creature has to come!” [P6]

"When he comes home, he would look for Frankie. After he takes off his jacket and stuff, he comes in and he looks for Frankie and he sits down and plays with him. And then after dinner time again, <child's name $>$ comes and plays with him. Bedtime he said he wants to put him in bed with him. So sometimes I leave him." [P5]

"My favourite thing to do with the creature was [to] watch TV, read. Sleep. Play with it. Draw. Make new friends!" [C7]

"She slept with me! [...] And she's always with me" [C6]

Every child named their toy and treated it as a living being that needed to be cared for, with feelings and mental states they seemed to take into consideration. For example, most children (7/11) were very protective of the toy and looked after 'its feelings', e.g. by making a bed for it to sleep in or clothes so that it wouldn't be 'cold', making sure to soothe it when it was getting 'stressed', and being very particular about how others could interact with it in fear that they would 'stress it', break it or take it from them.

"He was a little bit stressed, so I moved him right here.. And I, I.. wanted to put a blanket in there for his bed. And I put a nest in there for like a little... toy.” [C4]

"So I made him a little bed because he was starting to get really tired. [...] It was made out of my tie, and my V-neck jumper. I didn't have anything else with me." [C6]

"Well, for the first two nights she slept in a pillow down there (pointing to a spot on the living room floor, next to an armchair). I had a blanket for her, but then I thought.. just to keep her a bit more warm, she could stay at my bed." [C8b]

"You get very directed on how to use the creature. "Do this to the creature, don't do that to the creature". The second it vibrates he takes it away from you. (laughs) [...] I'm allowed to rub Creature, I'm allowed to pat Creature. But I'm not allowed to do anything else." [P6]

Another indication of children's emotional connection to the toy was that every child was sad to part with the toy, as was reported either by children themselves or by their parents. Beyond the interview data, this was also experienced by the first 


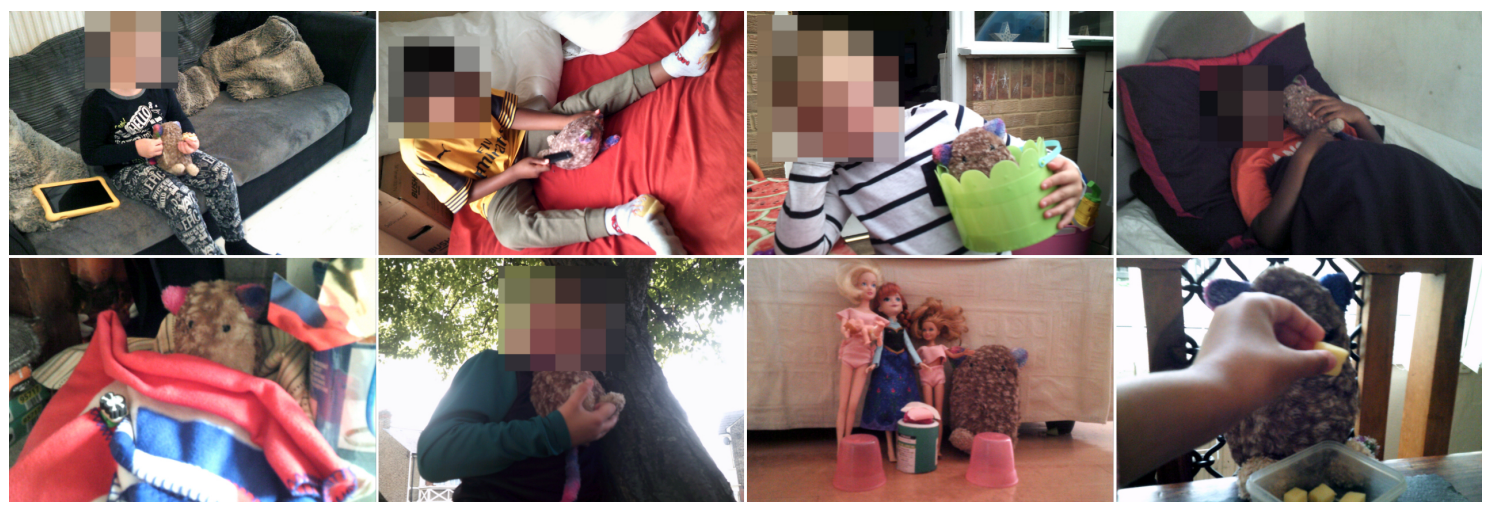

Figure 3. Example photos taken by children

author during her visits to pick up the toy, when most children would ask to keep the toy for longer, or would hide it and pretend they didn't know where it was. Seeing these strong impacts with the first 3 children, we decided to make repeated check-ins with the parents (at about a week and then 4 weeks post-deployment) to make sure this was only a transient state, as well as slightly alter the narrative when deploying the toy to add that the 'creature' would be returning to its family at the end of the week. We presumed that this framing would resonate with children and make it easier for them to part with the toy, thus lessening the emotional impact of the separation. Parents did not report any persisting issues during the phone check-ins; instead, they emphasized that children had fond memories of the toy and would still occasionally mention it.

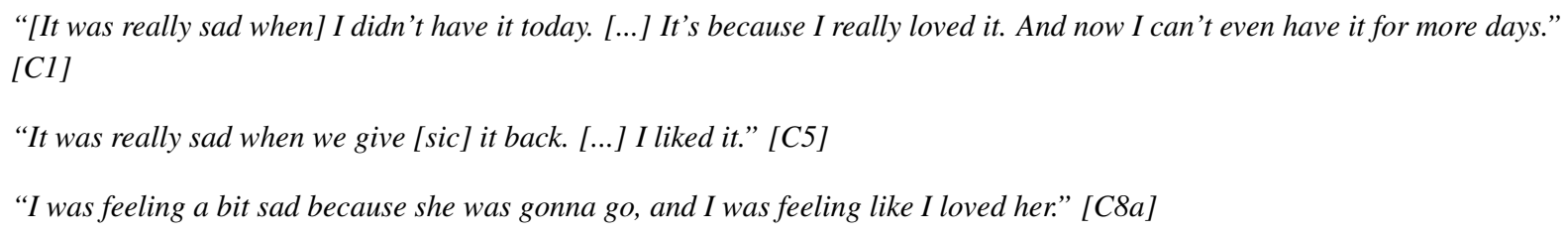

Children's sustained engagement with the toy appears to stem from the enjoyment they gained from the in-the-moment interaction. All families reported that interacting with the toy had a positive impact on children's mood; a finding that is discussed in more detail in the following section. Additionally, more than half of the parents (7/10) highlighted the sense of responsibility the back-story instilled in children as something that children really enjoyed and that in turn drove consistent engagement over the week-long deployment.

\begin{abstract}
"I really liked seeing [my child] sort of follow through and want to finish the tasks. [...] And I'm not sure if that was because it was something he was building a relationship with or just because he felt that responsibility and he was enjoying it.. I don't know! I think he just really enjoyed the whole process and you could just-I could see that anyway!” [P9]
\end{abstract}

"It gave him something to concentrate on, really.. To look after. Even though we've had other things for him to look after, that.. he seems to have wanted to and enjoyed it." [P10]

“'When I tried calming the creature down, Ifelt'.. I felt like I was actually doing something useful.” [C8a]

"I was feeling like laughing, and I was happy, because I made.. Because I was taking care of her." [C7]

\title{
Impact on emotion regulation
}

Both parents and children reported that the toy was incorporated into children's emotion regulatory practices in a number of contexts, and all parents recognised that the interaction with the toy had a calming effect on their children. Common observations included children naturally interacting with the toy to self-soothe after an emotion-eliciting situation, such as a conflict with their parents or siblings, or in moments they wanted to relax, such as before bedtime. While these emotion regulatory effects were most commonly observed in situations where children were particularly upset or angry, it was also reported that having the toy had an overall calming effect, with children appearing "a lot calmer" or "more settled" over the duration of the deployment.

"She got upset, and then she took Coco and she just calmed down and she laid down. If she was sent to her room, she'd go up to her bed and just lay down with Coco." [P2] 
"I mean like with this toy she's able to calm down a lot faster than like I said before, just going into her room and... tantrum and whatnot." [P3]

"It takes off a lot of the pressure. Having that go-to, where you know there's something that for sure that will calm him. Because... The thing is, it's a very hit-and-miss when it comes to calming him. With all other emotions you can kind of... settle it a bit. Like if he's angry, you can reduce the anger by taking him out of the situation, or if you have to, by pinning him down. If he's sad you can cheer him up... But with anxiety, it is the one that is too much for him. And no matter how anxious he gets you can't always keep him calm, and it comes out in his behaviour. So for him, having that has kept his anxiety quite low. And even when things that happened that normally would have set him off, haven't! Which is unbelievable to be honest. Honestly, I'd never thought I'd see something that would actually keep him quite so calm. [...] My house has been a lot calmer! (chuckles) It's been so much more peaceful for the past week. There haven't really been any attitude... Like... Just his whole entire behaviour has been awesome." [P6]

“Actually, he's been good this week. Because he had a home visitor, as well, from school, and he's.. He calmed down a lot! You know, even today at school when he went to meet his teacher, he seemed a lot more settled. So yeah, he has calmed down a lot for the past week. And I'm hoping that Frankie has something to do with it! (laughs)[...] I think it does. Because he has him every single day. Apart from that evening when we couldn't find him; we found him and then the following morning he straight away picked him up." [P5]

These parental reports were complemented by the child interviews: Ten out of the eleven children deliberately used the toy to calm down and reported that soothing the toy had a positive effect on their mood, making them feel "happy" or "calm". Four of the children also used the toy at times they were in physical pain and described how this helped them cope with it.

"C: When I tried calming the creature down, I felt.. happy! R: Why did you feel happy? G: Because I like petting him, hugging him!"”, [C2]

" $C$ : I was really sad when [my sibling] punched me in the bladder!

R: Oh, did he? Naughty [sibling]! And what did you afterwards? How did you calm down? C: I told mummy. And gave Happy a hug!" [C9]

"Mum: What did [your sibling] do? Did you just go in the bedroom this time and he told you off?

C: He told me to get out, that it's not mine.

M: Okay. But it is your bedroom.

$R$ : Oh, so that made you angry?

(child nods)

$R$ : What did you do afterwards to calm down?

$C:$ I ran in, got past [sibling's name] and started stroking the creature and hugging it.

$R:$ And how did that make you feel?

C: Really happy.. Overjoyed I would say.” [C10]

" $R$ : And how did that made you feel, when you had Creature and you were playing on your tablet?

$C$ : I felt really happy... And then this stopped hurting, this stopped hurting, and this stopped hurting (pointing to his bruises and scratches from a fall)." [C6]

"When my mum was brushing my hair.. it hurts, so I usually have the creature by me so it can distract me from the pain." [C8b]

While children seemed to engage with the toy naturally during emotional moments, half of of the parents (5/10) also mentioned instances where they would explicitly encourage their children to use it to soothe themselves. Only one parent (P1, quote below) mentioned that the toy was not on their or their child's mind in highly emotional situations like meltdowns, and they thought the child needed to cool down first before they could interact with the toy in a calm manner.

"I saw her looking after Winter, hugging Winter, calming Winter down, using it to calm herself down. [...] Especially like when she got angry. I'm like (speaking softly) "Go and get Winter”. [...] So, yeah, sometimes I'll direct her, sometimes she will just do it herself.", [P3]

"I know a problem is that sometimes when they're angry it's not really the first thing that comes to head. Because, you know, when a child is angry, they're angry! Do you understand? Maybe it's just when they cool down, then that's when they might think "you know what? Let me.." (imitates stroking movement). And then that's when they start cooling down even more." [P1] 


\title{
Parental views on the causes of observed effects
}

Some parents made their own inferences as to how the toy worked to help their children calm down. Most (6/10) reported that the toy was comforting for children, with a few drawing a comparison between the toy and their children's comfort objects, i.e. items they cherished and used to comfort themselves when younger, such as blankets or soft toys. Two of the parents and one child described how the sense of responsibility children felt for the toy made them shift their attention to caring for it rather than focusing on what might have been upsetting them, thus serving as a distraction. One parent (P6) thought the toy gave her child a sense of control over the toy's emotions that he was usually lacking in himself; the child's account seems to support this claim as he mentioned that he liked deliberately stressing the toy so he could soothe it and himself in doing so.

\footnotetext{
"I think it was comforting for her.. As I said, it was a lot like having her blankie when she's.. It's like a comfort... Yeah... When she came home from school, she'd grab hold of it and... [...] It sort of soothes her when she's feeling stressed or... It just makes her feel safer I think." [P7]
}

\begin{abstract}
"Because my mind was on her, and calming her down.. like she was a child to me. Because when I'm calming her down. technically my mind is completely on her. So I'm technically blocking out everything and trying to keep my child safe!” [C8b]

“Parent: It's something that I think... Like I said, he can control to an extent. Obviously, he can't control when it gets upset. But it's something that he has control over, because he doesn't have control over those specific emotions in him. [...] So it's the one thing that he can't control in himself, but he can control in something else. And I think, that really worked with him... I really do.

Child (independently): We can do this (cuddles the toy) and do this (presses toy's ears) if he just keeps purring and you want him to get mad and then make him purr again.I like calming him down.. because when he's just purring it's just... it makes me calm.” [P6 \& C6]
\end{abstract}

Interestingly, parents' accounts suggest that, in their view, the toy's impact on emotion regulation was not limited to children. Full half of the parents (5/10) reported that they found the interaction with the toy calming for themselves or other members of the family too, such as younger siblings or other adults.

\begin{abstract}
"And this morning, as I said, it was really... it helped me. I thought, "Oh! If I haven't tried it, I could never believe that". I thought that it would be a human being that could help me. I wasn't talking to anyone as I always do. And I wasn't praying or anything.. I just put this thing to my chest and it just worked. And I'm just telling you the truth. It did! Yeah, it did! (laughs)” [P5]

"I mean I actually enjoyed the little cuddles I had with the creatures! (chuckles) It was very calming, very.. It was a nice toy." [P8]

"Definitely, it can help both the mother and the child. Definitely. Which is a good thing because sometimes, some toys, people just create them just to help the child. But then, knowing there's something that can help the adult as well, it's even a plus! Because the same way a child needs help, the adult needs it as well. Because we get mad as much as they do! [...] It's nice to know that there's something that can help both!" [P1]
\end{abstract}

\section{Parents' acceptance of the intervention}

Parents reported that the toy had met - or in some cases even exceeded - their initial expectations and did not have any negative feedback to relay. Parents' accounts suggest that they held positive views of the toy and enjoyed their experience of having it at home. Notably, a parent (P4) who was initially sceptical about her child's interest in the toy and expected that it would quickly wane, described how surprised she was with her son's strong attachment to the toy and how caring he was with it. Finally, almost every parent $(9 / 10)$ reported that they would like to keep the toy at home for longer if possible, and inquired if and when it would be made available to the public. Most parents (9/10) thought that the toy would continue to be a valuable resource for the children as "somewhere they could go to" to calm down when needed.

"I'm impressed! I didn't think it would be the way it has. And I didn't expect the attachment. Really, really didn't. Especially him being a boy and being six. [...] I personally wouldn't change anything. I think it's great the way it is. There's nothing I can say 'Oh, you should add this, or take away that'.. [...] Because it's worked!' [P4]

"[What I enjoyed the most was] just watching her care for someone. Because sometimes, I do, like, "Look after your sister, come on.." trying to develop that in her. Because I feel that it hasn't, you know, that kind of caring side? But I saw she was able to do that with Coco. So I was like "Okay, she's very caring, and compassionate"." [P2] 
"I liked being able to refer to it, like when it was needed. And sometimes I just liked.. hugging him! (chuckles) Or like seeing [my children] hug him. [...] I'll be quite sad to let it go (chuckles). Cos you'd think they're quite inanimate, but they're also quite giving!" [P9]

"If they were on sale, I would happily buy one for him, really. I honestly do think it's such an amazing idea. [...] He just seemed to be coping better with him.” [P6]

"Knowing that there's a toy that is calming and soothing for them, to remind and say if they are getting upset or worked up or something, would be quite useful. Like when we said "Look, let's turn around and go and get your creatures". So a particular toy that's associated with calming them down and they can care for and look after. and that would purr and the feeling of that warmth and the realness of them close to them.. I think if there are difficult times it would be useful." [P8]

\section{Quantitative log data results}

In this section, we are reporting on the interaction data automatically collected by the toy during the deployments. Overall, the log data supports the qualitative observations, showing sustained engagement throughout the deployment: the families used each toy, on average, for 74.9 active minutes $^{1}$ per day (median $=60.5$; SD $=64.1$ ). See Figure 4 for box plots for individual children. We did observe that overall, the average interaction times per day were longer for the first three days of the deployments compared to the last three days - but even then the average active engagement was 43.8 minutes per day (median $=30.5, \mathrm{SD}=35.7$ ). This might indicate that the engagement was stronger in the first few days due to novelty effects and children's interest in the toy started to wane towards the end of the deployment. Another plausible explanation that would be in line with interview data is that in the first days, children and other family members interacted more with it as they were exploring the features, whereas in the last three days children already knew how the toy worked and used it as and when they needed it. Longer term deployments are needed to understand the stability of engagement beyond the first week.

As expected, we observed stronger engagement on weekends and holidays when most children would interact frequently with the toy throughout the day, whereas on school days, children interacted with it the most early in the morning (before school) and in the afternoon. To illustrate this, Figure 5 visualises the weekly active minutes for Child 7, selected as a typical example ${ }^{2}$. For example, comparing the data on a weekend day (Sat 22nd) and on a school day (Wed 26th) suggests how the active times have been influenced by school times: with the child having frequent interactions with the toy from the morning up to the evening on the weekend day, while briefly engaging with the toy in the morning before school and throughout the afternoon after their return on the school day. The log data also seem to confirm participants' reports that children would at times interact with the toy around bedtime to relax. In some cases, interactions were also registered at night time, suggesting that children had the toy in bed with them; due to the inherent limitations of the log data in terms of interpretability, we cannot ascertain if these touch traces represent intentional (e.g., children waking up in the middle of the night and stroking the toy) or accidental interactions.

Children's gender and age did not appear to influence their engagement with the prototype, as similar patterns of interaction were observed across all participants. When all interaction data is aggregated, the most frequently activated sensor was that of the back (35\%), followed by the gyroscope (26\%), feet (20\%) and ears (20\%). The large percentile of back sensor activation is consistent with the patterns of interaction reported in participants' interviews, as hugging and stroking the toy's back-both of which would activate the back sensor-were reported as children's preferred soothing interactions. Although the percentile of gyroscope activation was higher than we expected, considering it consistently happened alongside the activation of the back sensor, it does not seem likely that it indicates shaking or rough handling by children.

\section{Discussion}

\section{Principal findings}

The aim of this qualitative in-situ study was to investigate the engagement, acceptability, and initial subjective indicators of emotion regulatory effects for a proof-of-concept intervention model, as instantiated in a 'Smart Toys' prototype. The novelty of the proposed approach was to deliver at-home interventions through an interactive object that becomes incorporated into child's everyday interactions to provide in-the-moment regulatory support, without any explicit training necessary for the child or the parent.

The fundamental assumptions underpinning the logic model of such 'situated and child-led' intervention was that (i) children will be naturally compelled to keep interacting with the intervention without external guidance; (ii) that it will become

\footnotetext{
${ }^{1}$ As outlined in the Data Analysis section, we classify any given minute as active only if the toy logged at least 20 different sensor interactions during that 1 min interval. This is to avoid counting accidental touches, or just moving toy from one place to another.

${ }^{2} \mathrm{C} 7$ 's overall active minutes length is close to the median of the dataset and also qualitatively typical to the interaction patterns we observed for other children.
} 
Active minutes per day

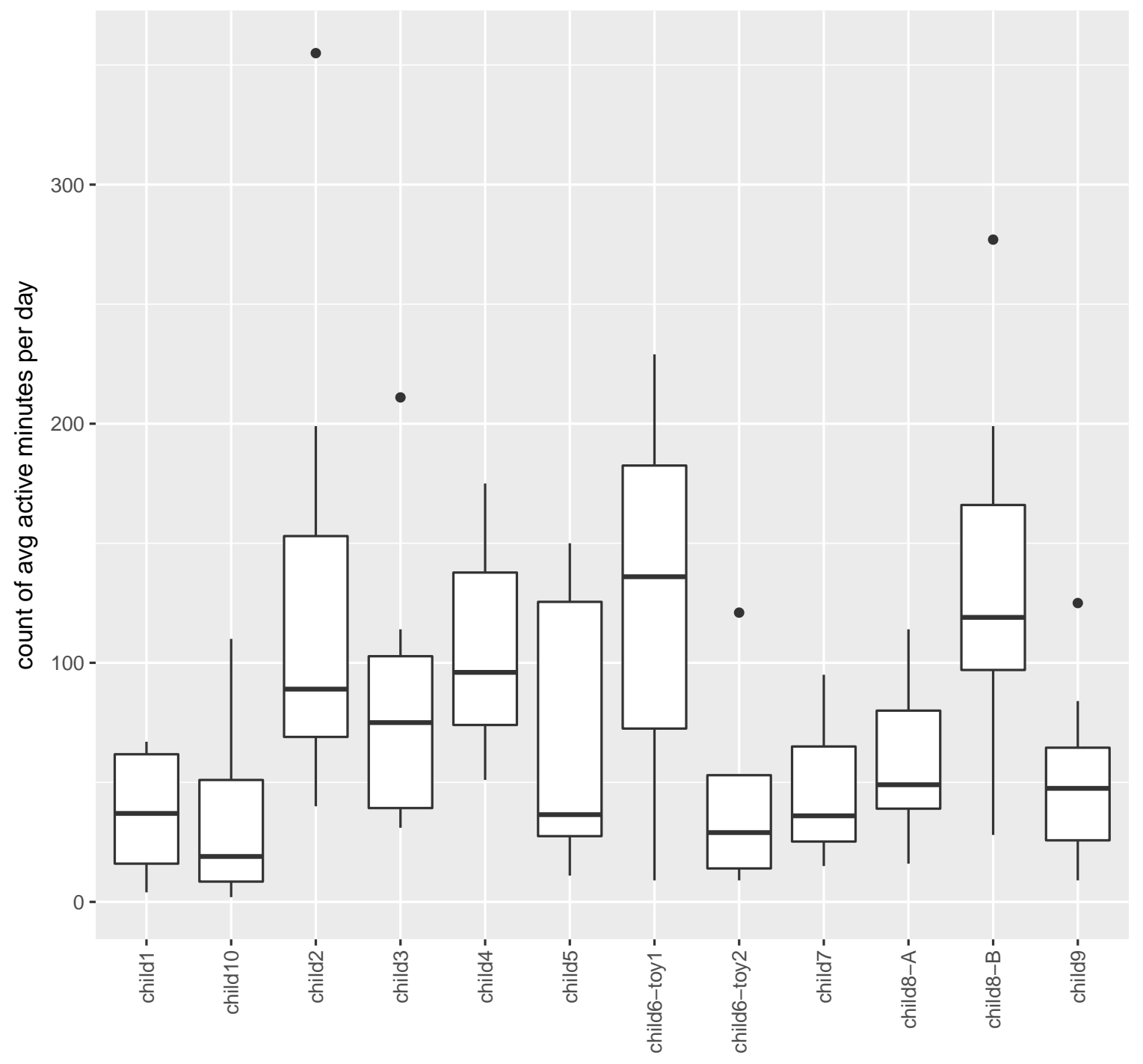

Figure 4. Box plots for active minutes of interaction per day for individual children 


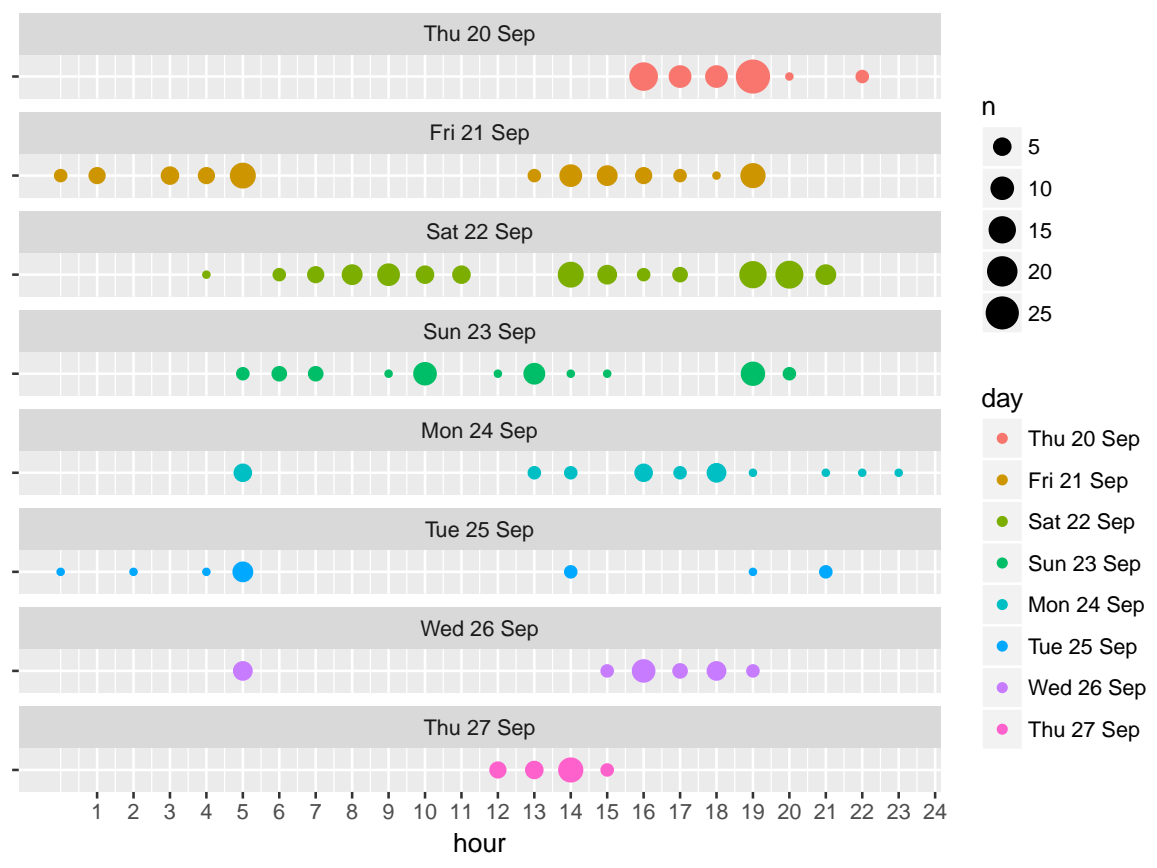

Figure 5. Example day-to-day summary for a child (C7)

incorporated into their everyday emotion regulatory practices, even without any formal training; and finally (iii) that the intervention will be perceived as acceptable to parents. The qualitative findings described above suggest that all three conditions were satisfied: All children reported sustained engagement with the prototype, without any externally imposed conditions; and have been consistently labelling such interactions as subjectively pleasing. Both parents and children further described the observed emotion regulatory effects of child-toy interaction, under a variety of contexts (e.g., self-soothing after an interpersonal conflict, reduction in subjective anxiety levels, relaxation support, coping with pain). Finally, all children and 9/10 parents were keen on keeping the prototype for longer, suggesting high acceptability and fit with social practices in the home.

The qualitative findings also provided some indicative support for the hypothesised mechanisms underpinning the first two levels of the logic model: Level 1 as facilitating in-the-moment regulatory support (relying on attentional deployment and response modulation); and Level 2 as scaffolding ongoing engagement (through the creation of an emotional attachment to the toy). For Level 1, the experiences described by both parents and children supported the in-the-moment regulatory effects: the children described the moments of holding the prototypes as 'happy' and 'calming', and some have reported to deliberately seek the interaction to calm down. Interestingly, half of the parents have described similar soothing experiences themselves, suggesting that the effects might be consistent across a wider age range; as could be expected given the reliance on fundamental emotion-regulatory mechanisms ${ }^{65,71,73,76,77}$. While it is impossible to disentangle the assumed attentional deployment and response modulation mechanisms based on the retrospective interview data, the stories captured in the interviews provide some support for the hypothesis that physiological effects arise from a combination of tactile stimulation (e.g., 'I just put it to my chest and it worked' type of quotes common across the dataset) and more conscious focus on "changing the creature's emotions".

Similarly, the hypothesised Level 2 mechanisms have received indicative support in the interview dataset. All children referred to the prototype as if it were alive, attributing a range of human-like mental states to the toy, together with an associated range of caring behaviours (e.g., making a bed or custom-made clothes to help it 'feel warm', making sure it is not 'stressed', controlling how others interact so as to not 'hurt it' etc). Combined with the sadness associated with the end of deployment, these observations suggest that the prototype was successful in generating an emotional attachment, which appeared to facilitate the continued engagement. These relationship-building effects appear analogous to those observed with other animal-like robots in other contexts: see $^{99}$ for a critical analysis of the mechanisms behind such computational devices presenting themselves as 'relational artifacts'.

The current data does not provide indications of any effects on longitudinal shifts in emotion regulatory practices (Level 3), due to the short term deployment and lack of baseline and follow-up measurements. 
Similarities and differences to existing interventions To best of our knowledge, the proposed intervention model is unique in prevention science by suggesting an intervention delivery method that becomes fully embedded in children's everyday lives, does not require any explicit training, and is relying on in-the-moment experiential support rather than information delivery. It draws inspiration from the large body of research on animal-assisted interventions (see ${ }^{100}$ for a review), which has suggested promising outcomes in a number of populations. These include increased social interaction among children with autism spectrum disorder ${ }^{101}$, increased social behaviours and reduced agitation and aggression among persons with dementia ${ }^{102}$, reduction in symptoms among patients with depression ${ }^{103}$, and increased emotional well-being such as reduced anxiety and fear ${ }^{104}$. A related area of work is focused on 'social assistive robots' ${ }^{81,101-104}$, which are designed to act as pet surrogates, such as the robotic seal Paro ${ }^{105}$. Majority of such SAR interventions has so far, however, focused on occasional use by older adults, particularly those suffering from dementia ${ }^{105-110}$. The design of SAR with typically developing children has been limited to educational interventions outside of mental health domain ${ }^{111-113}$. Despite the reported promising outcomes of SAR interventions in other contexts, no studies to date explored the use of SARs as part of prevention interventions (for emotion regulation or other protective factors) with typically developing children, and only one recent study ${ }^{80}$ has explored the effects of interacting with Paro robot on children's mood, anxiety, and arousal after exposure to a lab-based stress-inducing task: interaction with the robot resulted in greater increases in positive mood than any of the two control conditions, but did not have a significant effect on negative mood, anxiety, or arousal.

\section{Strengths and limitations}

One strength of the study was the emphasis on in-situ unstructured deployments, which provided ecologically valid data about possible appropriation in families. All parents were from under-privileged neighbourhoods and many were in difficult personal situations; we have avoided tapping into the proverbial 'worried well' and instead worked with a population who could be expected to strongly benefit from emotion regulation interventions (cf., $\left.{ }^{114-116}\right)$. The detailed interviews then provided a holistic understanding of how the prototypes have been used, and the impact they might have on the family life. Another strength was including the interview data from both parents and children (in addition to photographs collected by participants during the week), triangulating the evidence across all stakeholders.

The data has been promising in terms of observed engagement and acceptability, which were high across all 10 families recruited into the study. This consistency — together with analogous positive effects from earlier deployment ${ }^{64}$ —is particularly promising in view of the commonly high attrition rates and non-engagement for technology-enabled mental health interventions $^{10,38-41}$. However, there may have been some self-selection recruitment effects: the families have explicitly opted into the study and thus might be more likely to respond positively then 'general' population. Further studies should investigate the engagement rates when deployed, e.g., as part of school-based approaches and with reduced researchers' engagement (e.g. questionnaire rather than interview methods).

An expected limitation of a pilot qualitative study is the lack of definitive data on psychological effects. While participants' reports suggest that they experienced subjectively significant changes to their everyday emotion regulatory practices, more rigorous studies are necessary to understand the strength of psychological effects and whether these would scale up. In particular, it is not yet clear if these would lead to long-term changes, and whether the magnitude would lead to a clinically significant change in emotion-coping mechanisms and strategies ${ }^{45}$. As such, the lack of data on the presumed Level 3 effects is the most important gap. It will require not only rigorous efficacy study designs to estimate the current effects, but also likely further iterative co-design development (with parents, children, and prevention science experts) to strengthen the intervention impact. The qualitative pilot data from this and previous publication ${ }^{64}$ provide a good starting point for such future work.

\section{Conclusions}

This is the first known study investigation of the use of object-enabled intervention delivery to support emotion regulation in-situ. To understand the feasibility of such novel intervention mechanism, this qualitative study examined its appropriation and engagement by 11 children from low-SES families over the period of one week. Triangulating both parental and child interviews, the data provides a holistic picture of how the prototype was incorporated into the family life. The strong engagement and qualitative indications of effects are promising - children were able to use the prototype without any training and incorporated it into their emotion regulation practices during daily challenges. Future work is needed to extend this indicative data with larger studies examining the psychological efficacy of the proposed intervention. More broadly, our findings suggest the potential of a technology-enabled shift in how prevention interventions are designed and delivered: empowering children and parents through 'child-led, situated interventions', where participants learn through actionable support directly within family life, as opposed to didactic in-person workshops and a subsequent skills application. 


\section{References}

1. Houtrow, A. J., Larson, K., Olson, L. M., Newacheck, P. W. \& Halfon, N. Changing trends of childhood disability, 2001-2011. Pediatrics 134, 530-538 (2014).

2. Kessler, R. C. \& Wang, P. S. The descriptive epidemiology of commonly occurring mental disorders in the United States. Annu. Rev. Public Heal. 29, 115-129 (2008).

3. Merikangas, K. R. et al. Prevalence and treatment of mental disorders among US children in the 2001-2004 NHANES. Pediatrics 125, 75-81 (2010).

4. Green, H., McGinnity, Á., Meltzer, H., Ford, T. \& Goodman, R. Mental health of children and young people in Great Britain, 2004. (2005).

5. Polanczyk, G. V., Salum, G. A., Sugaya, L. S., Caye, A. \& Rohde, L. A. Annual Research Review: A meta-analysis of the worldwide prevalence of mental disorders in children and adolescents. J. Child Psychol. Psychiatry 56, 345-365 (2015). DOI 10.1111/jcpp.12381.

6. Merikangas, K. R. et al. Lifetime prevalence of mental disorders in US adolescents: results from the National Comorbidity Survey Replication-Adolescent Supplement (NCS-A). J. Am. Acad. Child \& Adolesc. Psychiatry 49, 980-989 (2010).

7. Costello, E. J. \& Sampson, N. A. Services for adolescent psychiatric disorders: 12-month data from the National Comorbidity Survey-Adolescent. Psychiatr. Serv. 359-366. DOI 10.1176/appi.ps.201100518.Services.

8. Wykes, T. et al. Mental health research priorities for Europe. The Lancet Psychiatry 2, 1036-1042 (2015). DOI 10.1016/S2215-0366(15)00332-6.

9. Mental Health Taskforce. The five year forward view for mental health. Tech. Rep. (2016).

10. National Institute of Mental Health. Opportunities and Challenges of Developing Information Technologies on Behavioral and Social Science Clinical Research. Tech. Rep. (2017).

11. World Health Organization. Prevention of Mental Disorders: Effective Interventions and Policy Options. Tech. Rep., Geneva (2004). DOI 10.7202/032301ar.

12. Greenberg, M. T. School based prevention : current status and future challenges. Eff. Educ. 2, 27-52 (2010). DOI $10.1080 / 19415531003616862$.

13. Patton, G. C. et al. Our future: a Lancet commission on adolescent health and wellbeing. The Lancet 387, 2423-2478 (2016). DOI 10.1016/S0140-6736(16)00579-1.

14. Payton, J. \& Wardlaw, D. Social and emotional learning: A framework for promoting mental health and reducing risk behavior in children and youth. J. Sch. Heal. (2000).

15. Weisz, J. R., Sandler, I. N., Durlak, J. A. \& Anton, B. S. Promoting and Protecting Youth Mental Health Through Evidence-Based Prevention and Treatment. Am. Psychol. 60, 628-648 (2005). DOI 10.1037/0003-066X.60.6.628.

16. Weare, K. \& Nind, M. Mental health promotion and problem prevention in schools: what does the evidence say? Heal. Promot. Int. 26, i29-i69 (2011). DOI 10.1093/heapro/dar075.

17. Adi, Y., Kiloran, A., Janmohamed, K., Stewart-Brown, S. \& Killoran, A. Systematic review of the effectiveness of interventions to promote mental wellbeing in primary schools - Universal approaches which do not focus on violence or bullying. Tech. Rep. December 2007, National Institute of Health and Clinical Excellence Report (NICE) (2007).

18. Bailey, R., Stickle, L., Brion-Meisels, G. \& Jones, S. M. Re-imagining social-emotional learning: Findings from a strategy-based approach. Phi Delta Kappan 100, 53-58 (2019). DOI 10.1177/0031721719827549.

19. Mcclelland, M. M. et al. SEL Interventions in Early Childhood. Futur. children 27, 33-47 (2017).

20. Jones, S. M. et al. Navigating social and emotional learning from the inside out; Looking inside and across 25 leading SEL programs: A practical resource for schools and OST providers (elementary school focus) (2017).

21. Durlak, J. A., Weissberg, R. P., Dymnicki, A. B., Taylor, R. D. \& Schellinger, K. B. The impact of enhancing students' social and emotional learning: a meta-analysis of school-based universal interventions. Child development 82, 405-32 (2011). DOI 10.1111/j.1467-8624.2010.01564.x.

22. Jones, S. M. \& Bouffard, S. M. Social and Emotional Learning in Schools: From Programs to Strategies. Social Policy Report. Volume 26, Number 4. Soc. for Res. Child Dev. (2012).

23. Weissberg, R. P. Promoting the Social and Emotional Learning of Millions of School Children. Perspectives on Psychol. Sci. 14, 65-69 (2019). DOI 10.1177/1745691618817756. 
24. Greenberg, M. T., Domitrovich, C. E., Weissberg, R. P. \& Durlak, J. A. Social and Emotional Learning as a Public Health Approach to Education. The Futur. Child. 27, 13-32 (2017).

25. Taylor, R. D., Oberle, E., Durlak, J. A. \& Weissberg, R. P. Promoting Positive Youth Development Through School-Based Social and Emotional Learning Interventions: A Meta-Analysis of Follow-Up Effects. Child Dev. 88, 1156-1171 (2017). DOI 10.1111/cdev.12864.

26. Webster-Stratton, C. \& Hammond, M. Treating children with early-onset conduct problems: a comparison of child and parent training interventions. J. consulting clinical psychology 65, 93-109 (1997). DOI 10.1037/0022-006X.65.1.93.

27. Reid, M. J., Webster-Stratton, C. \& Hammond, M. Enhancing a classroom social competence and problem-solving curriculum by offering parent training to families of moderate-to high-risk elementary school children. J. Clin. Child Adolesc. Psychol. 36, 605-620 (2007).

28. Belfield, C. R., Nores, M., Barnett, S. \& Schweinhart, L. The High/Scope Perry Preschool Program: Cost Benefit Analysis Using Data from the Age-40 Followup. J. Hum. Resour. XLI, 162-190 (2006). DOI 10.3368/jhr.XLI.1.162.

29. Dray, J. et al. Systematic Review of Universal Resilience-Focused Interventions Targeting Child and Adolescent Mental Health in the School Setting. J. Am. Acad. Child Adolesc. Psychiatry 56, 813-824 (2017). DOI 10.1016/j.jaac.2017.07.780.

30. Masten, A. S. Ordinary Magic Resilience Processes in Development. Am. Psychol. 56, 227-238 (2001). DOI 10.1037/0003-066X.56.3.227.

31. Masten, A. S. \& Obradović, J. Competence and resilience in development. Annals New York Acad. Sci. 1094, 13-27 (2006). DOI 10.1196/annals.1376.003.

32. Greenberg, M. T. Promoting resilience in children and youth: preventive interventions and their interface with neuroscience. Annals New York Acad. Sci. 1094, 139-50 (2006). DOI 10.1196/annals.1376.013.

33. Luthar, S. S. Resilience in development: A synthesis of research across five decades. Dev. Psychopathol. Vol. Three: Risk, Disord. Adapt. 739-795 (2015).

34. Bar-On, R., Maree, K. \& Elias, M. Educating people to be emotionally intelligent (Greenwood Publishing Group, 2007).

35. Torous, J., Staples, P. \& Onnela, J.-P. Realizing the potential of mobile mental health: new methods for new data in psychiatry. Curr. psychiatry reports 17, 61 (2015).

36. Onnela, J.-P. \& Rauch, S. L. Harnessing Smartphone-Based Digital Phenotyping to Enhance Behavioral and Mental Health. Neuropsychopharmacology 41, 1691-1696 (2016). DOI 10.1038/npp.2016.7.

37. Mohr, D. C., Zhang, M. \& Schueller, S. M. Personal Sensing: Understanding Mental Health Using Ubiquitous Sensors and Machine Learning. Annu. Rev. Clin. Psychol 13, $23-47$ (2017). DOI 10.1146/annurev-clinpsy-032816.

38. Eysenbach, G. The law of attrition. J. Med. Internet Res. 7, 1-9 (2005). DOI 10.2196/jmir.7.1.e11. arXiv: 1011. $1669 \mathrm{v} 3$.

39. Torous, J., Nicholas, J., Larsen, M. E., Firth, J. \& Christensen, H. Clinical review of user engagement with mental health smartphone apps: Evidence, theory and improvements. Evidence-Based Mental Heal. 21, 116-119 (2018). DOI 10.1136/eb-2018-102891.

40. Mohr, D. C., Weingardt, K. R., Reddy, M. \& Schueller, S. M. Three problems with current digital mental health research... and three things we can do about them. Psychiatr. Serv. 68, 427-429 (2017). DOI 10.1176/appi.ps.201600541.

41. Mohr, D. C., Riper, H. \& Schueller, S. M. A Solution-Focused Research Approach to Achieve an Implementable Revolution in Digital Mental Health. JAMA Psychiatry 75, 113 (2018). DOI 10.1001/jamapsychiatry.2017.3838.

42. Stern, R. S., Harding, T. B., Holtzer, A. A. \& Elbertson, N. A. Current and potential uses of technology to enhance SEL: What's Now and What's next? In Handbook of Social and Emotional Learning: Research and Practice, 516-531 (2015).

43. Slovak, P., Thieme, A., Tennent, P., Olivier, P. \& Fitzpatrick, G. On Becoming a Counsellor: Challenges and Opportunities To Support Interpersonal Skills Training. In CSCW'15, 1336-1347 (2015).

44. Moffitt, T. E. et al. A gradient of childhood self-control predicts health, wealth, and public safety. Proc. Natl. Acad. Sci. 108, 2693-2698 (2011). DOI 10.1073/pnas.1010076108.

45. Aldao, A., Nolen-Hoeksema, S. \& Schweizer, S. Emotion-regulation strategies across psychopathology: A meta-analytic review. Clin. Psychol. Rev. 30, 217-237 (2010). DOI 10.1016/j.cpr.2009.11.004. 95/57289.

46. Berenbaum, H., Raghavan, C., Le, H., Vernon, L. L. \& Gomez, J. J. A taxonomy of emotional disturbances. Clin. Psychol. Sci. Pract. 10, 206-226 (2003). 
47. Greenberg, L. S. Emotion-focused therapy: Coaching clients to work through their feelings (APA, Washington, 2002).

48. Kring, A. M. \& Bachorowski, J.-A. Emotions and psychopathology. Cogn. \& Emot. 13, 575-599 (1999).

49. Mennin, D. \& Farach, F. Emotion and evolving treatments for adult psychopathology. Clin. Psychol. Sci. Pract. 14, 329-352 (2007).

50. Buckner, J. C., Mezzacappa, E. \& Beardslee, W. R. Characteristics of resilient youths living in poverty: The role of self-regulatory processes. Dev. Psychopathol. 15, 139-162 (2003). DOI 10.1017/S0954579403000087.

51. Diamond, A., Barnett, W. S., Thomas, J. \& Munro, S. Preschool program improves cognitive control. Science 318, 1387-1388 (2007). DOI 10.1126/science.1151148. NIHMS 150003.

52. Webster-Stratton, C., Reid, M. J. \& Hammond, M. Preventing conduct problems, promoting social competence: a parent and teacher training partnership in head start. J. clinical child psychology 30, 283-302 (2001). DOI 10.1207/S15374424JCCP3003.

53. Kazdin, A. E. Developing Treatments for Antisocial Behavior Among Children : Controlled Trials and Uncontrolled Tribulations. Perspectives on Psychol. Sci. 13, 634-650 (2018). DOI 10.1177/1745691618767880.

54. Pina, L. et al. In Situ Cues for ADHD Parenting Strategies Using Mobile Technology. In Pervasive Health '14 (2014).

55. Lunkenheimer, E. S., Shields, A. M. \& Cortina, K. S. Parental emotion coaching and dismissing in family interaction. Soc. Dev. 16, 232-248 (2007). DOI 10.1111/j.1467-9507.2007.00382.x.

56. Katz, L. F. \& Hunter, E. C. Maternal meta-emotion philosophy and adolescent depressive symptomatology. Soc. Dev. 16, 343-360 (2007).

57. Ramsden, S. R. \& Hubbard, J. A. Family expressiveness and parental emotion coaching: Their role in children's emotion regulation and aggression. J. abnormal child psychology 30, 657-667 (2002).

58. Eisenberg, N., Fabes, R. a. \& Murphy, B. C. Parents' Reactions to Children's Negative Emotions : Relations to Children's Social Competence and Comforting Behavior. Child Dev. 67, 2227-2247 (1996). DOI 10.1111/j.14678624.1996.tb01854.x.

59. Gilliom, M., Shaw, D. S., Beck, J. E., Schonberg, M. A. \& Lukon, J. L. Anger regulation in disadvantaged preschool boys: strategies, antecedents, and the development of self-control. Dev. psychology 38, 222-235 (2002). DOI 10.1037/00121649.38.2.222.

60. Gottman, J. M., Katz, L. F. \& Hooven, C. Parental meta-emotion philosophy and the emotional life of families: Theoretical models and preliminary data. J. Fam. Psychol. 10, 243-268 (1996). DOI 10.1037//0893-3200.10.3.243.

61. Denham, S. A., Renwick-DeBardi, S. \& Hewes, S. Emotional communication between mothers and preschoolers: Relations with emotional competence. Merrill-Palmer Q. (1982-) 488-508 (1994).

62. Dunn, J., Brown, J. \& Beardsall, L. Family talk about feeling states and children's later understanding of others' emotions. Dev. Psychol. 27, 448 (1991).

63. Dunn, J., Brown, J., Slomkowski, C., Tesla, C. \& Youngblade, L. Young children's understanding of other people's feelings and beliefs: Individual differences and their antecedents. Child development 62, 1352-1366 (1991).

64. Slovak, P. et al. "I Just Let Him Cry ... ”: Designing Socio-Technical Interventions in Families to Prevent Mental Health Disorders. In Proceedings of the ACM on Human-Computer Interaction, vol. 2 (2018). DOI 10.1145/3274429.

65. Gross, J. J. Emotion Regulation: Current Status and Future Prospects. Psychol. Inq. 26, 1-26 (2015). DOI 10.1080/1047840X.2014.940781. arXiv:1011.1669v3.

66. Gordon, E., Schirra, S. \& Street, B. Playing with Empathy : Digital Role-Playing Games in Public Meetings. In ComTech 2011, July, 179-185 (2011).

67. Mohr, D. C. et al. Trials of intervention principles: Evaluation methods for evolving behavioral intervention technologies. J. Med. Internet Res. 17 (2015). DOI 10.2196/jmir.4391.

68. Slovak, P., Salen, K., Ta, S. \& Fitzpatrick, G. Mediating Conflicts in Minecraft: Empowering Learning in Online Multiplayer Games. In Proceedings of the 2018 CHI Conference on Human Factors in Computing Systems - CHI'18, Paper No. 595 (ACM Press, New York, New York, USA, 2018). DOI 10.1145/3173574.3174169.

69. Sheppes, G. \& Gross, J. J. Is Timing everything? Temporal considerations in emotion regulation. Pers. Soc. Psychol. Rev. 15, 319-331 (2011). DOI 10.1177/1088868310395778. 
70. Ford, B. Q. \& Gross, J. J. Emotion regulation: Why beliefs matter. Can. Psychol. 59, 1-14 (2018). DOI $10.1037 /$ cap0000142.

71. Aldao, A., Sheppes, G. \& Gross, J. J. Emotion Regulation Flexibility. Cogn. Ther. Res. 39, 263-278 (2015). DOI 10.1007/s10608-014-9662-4.

72. Sheppes, G. \& Gross, J. J. Emotion Regulation Effectiveness: What Works When. In Handbook of Psychology, 391-406 (Wiley-Blackwell Press, Indianapolis, 2012), 2nd edn.

73. Sheppes, G., Blechert, J. \& Gross, J. J. Emotion Regulation Choice : A Conceptual Framework and Supporting Evidence. 143 (2014).

74. Farb, N. A. S., Anderson, A. K., Irving, J. A. \& Segal, Z. V. Mindfulness Interventions and Emotion Regulation. In Handbook of Emotion Regulation, 548-567 (Guilford, New York, 2014).

75. Turkle, S. Authenticity in the age of digital companions. Interact. Stud. 8, 501-517 (2007). DOI 10.1075/is.8.3.11tur.

76. Beetz, A., Uvnäs-Moberg, K., Julius, H. \& Kotrschal, K. Psychosocial and psychophysiological effects of human-animal interactions: The possible role of oxytocin. Front. Psychol. 3, 1-15 (2012). DOI 10.3389/fpsyg.2012.00234.

77. Doré, B. P., Morris, R. R., Burr, D. A., Picard, R. W. \& Ochsner, K. N. Helping Others Regulate Emotion Predicts Increased Regulation of One's Own Emotions and Decreased Symptoms of Depression. Pers. Soc. Psychol. Bull. 43, 729-739 (2017). DOI 10.1177/0146167217695558.

78. Reeck, C., Ames, D. R. \& Ochsner, K. N. The Social Regulation of Emotion: An Integrative, Cross-Disciplinary Model. Trends Cogn. Sci. 20, 47-63 (2016). DOI 10.1016/j.tics.2015.09.003. 15334406.

79. Coan, J. a., Schaefer, H. S. \& Davidson, R. J. Lending a hand of the neural response to threat. Psychol. Sci. 17, 1032-1039 (2006). DOI 10.1111/j.1467-9280.2006.01832.x.

80. Crossman, M. K., Kazdin, A. E. \& Kitt, E. R. The influence of a socially assistive robot on mood, anxiety, and arousal in children. Prof. Psychol. Res. Pract. 49, 48-56 (2018). DOI 10.1037/pro0000177.

81. Rabbitt, S. M., Kazdin, A. E. \& Scassellati, B. Integrating socially assistive robotics into mental healthcare interventions: Applications and recommendations for expanded use. Clin. Psychol. Rev. 35, 35-46 (2015). DOI 10.1016/j.cpr.2014.07.001.

82. Cosley, B. J., McCoy, S. K., Saslow, L. R. \& Epel, E. S. Is compassion for others stress buffering? Consequences of compassion and social support for physiological reactivity to stress. J. Exp. Soc. Psychol. 46, 816-823 (2010). DOI 10.1016/j.jesp.2010.04.008.

83. Taylor, S. E. Social support: A review. In Friedman, H. S. (ed.) The Oxford handbook of health psychology, 189-214 (Oxford University Press, New York, NY, 2011). DOI 10.1093/oxfordhb/9780195342819.013.0009.

84. Hayashi, R. \& Kato, S. Psychological Effects of Physical Embodiment in Pet Therapy. Artif. Life Robotics 2016, 158-162 (2016). DOI 10.1007/s10015-016-0320-7.

85. Donath, J. Artificial pets: Simple behaviors elicit complex attachments. Encycl. Animal Behav. (2004).

86. Lee, H. R. et al. Asthmon: Empowering Asthmatic Children's Self-Management with a Virtual Pet. Proc. 28th international conference extended abstracts on Hum. factors computing systems - CHI EA '10 3583 (2010). DOI $10.1145 / 1753846.1754022$.

87. Gjersoe, N. L., Hall, E. L. \& Hood, B. Children attribute mental lives to toys when they are emotionally attached to them. Cogn. Dev. 34, 28-38 (2015). DOI 10.1016/j.cogdev.2014.12.002.

88. Schleider, J. L. \& Weisz, J. R. Implicit Theories Relate to Youth Psychopathology, But How? A Longitudinal Test of Two Predictive Models. Child Psychiatry Hum. Dev. 47, 603-617 (2016). DOI 10.1007/s10578-015-0595-2.

89. Tamir, M., John, O. P., Srivastava, S. \& Gross, J. J. Implicit Theories of Emotion: Affective and Social Outcomes Across a Major Life Transition. J. Pers. Soc. Psychol. 92, 731-744 (2007). DOI 10.1037/0022-3514.92.4.731.

90. Molden, D. C. \& Dweck, C. S. Finding "meaning" in psychology: A lay theories approach to self-regulation, social perception, and social development. Am. Psychol. 61, 192-203 (2006). DOI 10.1037/0003-066X.61.3.192.

91. Kneeland, E. T., Dovidio, J. F., Joormann, J. \& Clark, M. S. Emotion malleability beliefs, emotion regulation, and psychopathology: Integrating affective and clinical science. Clin. Psychol. Rev. 45, 81-88 (2016). DOI 10.1016/j.cpr.2016.03.008.

92. Halberstadt, A. G. et al. Development and Validation of the Parents' Beliefs about Children's Emotions Questionnaire. Psychol. Assess. 25, 1195-1210 (2013). DOI 10.1037/a0033695.Development. NIHMS150003. 
93. Ford, B. Q., Lwi, S. J., Gentzler, A. L., Hankin, B. \& Mauss, I. B. The cost of believing emotions are uncontrollable: Youths' beliefs about emotion predict emotion regulation and depressive symptoms. J. Exp. Psychol. Gen. (2017). DOI $10.1037 / x g e 0000396$.

94. De Castella, K. et al. Beliefs About Emotion: Links to Emotion Regulation, Well-Being, and Psychological Distress. Basic Appl. Soc. Psychol. 35, 497-505 (2013). DOI 10.1080/01973533.2013.840632.

95. Schroder, H. S., Dawood, S., Yalch, M. M., Donnellan, M. B. \& Moser, J. S. The Role of Implicit Theories in Mental Health Symptoms, Emotion Regulation, and Hypothetical Treatment Choices in College Students. Cogn. Ther. Res. 39, 120-139 (2015). DOI 10.1007/s10608-014-9652-6.

96. Veilleux, J. C., Salomaa, A. C., Shaver, J. A., Zielinski, M. J. \& Pollert, G. A. Multidimensional Assessment of Beliefs About Emotion: Development and Validation of the Emotion and Regulation Beliefs Scale. Assessment 22, 86-100 (2015). DOI 10.1177/1073191114534883.

97. Romero, C., Master, A., Paunesku, D., Dweck, C. S. \& Gross, J. J. Academic and emotional functioning in middle school: the role of implicit theories. Emotion 14, 227-34 (2014). DOI 10.1037/a0035490.

98. Braun, V. \& Clarke, V. Using thematic analysis in psychology. Qual. research psychology 3, 77-101 (2006).

99. Turkle, S. Relational Artifacts/Children/Elders: The Complexities of CyberCompanions. Cogn. Sci. Soc. 6273 (2005). DOI 10.1080/09540090600868912.

100. Crossman, M. K. Effects of Interactions With Animals On Human Psychological Distress. J. Clin. Psychol. 73, 761-784 (2017). DOI 10.1002/jclp.22410.

101. O'Haire, M. E. Animal-assisted intervention for autism spectrum disorder: A systematic literature review. J. autism developmental disorders 43, 1606-1622 (2013).

102. Bernabei, V. et al. Animal-assisted interventions for elderly patients affected by dementia or psychiatric disorders: a review. J. psychiatric research 47, 762-773 (2013).

103. Souter, M. A. \& Miller, M. D. Do Animal-Assisted Activities Effectively Treat Depression? A Meta-Analysis. Anthrozoos 20, 167-180 (2007). DOI 10.2752/175303707X207954.

104. Nimer, J. \& Lundahl, B. Animal-assisted therapy: A meta-analysis. Anthrozoos 20, 225-238 (2007).

105. Burton, A. Dolphins, dogs, and robot seals for the treatment of neurological disease. The Lancet Neurol. 12, 851-852 (2013). DOI 10.1016/S1474-4422(13)70206-0.

106. Inoue, K., Wada, K. \& Uehara, R. How effective is robot therapy?: Paro and people with dementia. In 5th European Conference of the International Federation for Medical and Biological Engineering, 784-787 (Springer, 2011).

107. Marti, P., Pollini, A., Rullo, A. \& Shibata, T. Engaging with artificial pets. In Proceedings of the 2005 annual conference on European association of cognitive ergonomics, 99-106 (University of Athens, 2005).

108. Moyle, W. et al. Exploring the effect of companion robots on emotional expression in older adults with dementia: A pilot randomized controlled trial. J. gerontological nursing (2013).

109. Robinson, H., MacDonald, B., Kerse, N. \& Broadbent, E. The psychosocial effects of a companion robot: a randomized controlled trial. J. Am. Med. Dir. Assoc. 14, 661-667 (2013).

110. Wada, K., Ikeda, Y., Inoue, K. \& Uehara, R. Development and preliminary evaluation of a caregiver's manual for robot therapy using the therapeutic seal robot Paro. In RO-MAN, 2010 IEEE, 533-538 (IEEE, 2010).

111. Short, E. et al. How to train your DragonBot: Socially assistive robots for teaching children about nutrition through play. IEEE RO-MAN 2014 - 23rd IEEE Int. Symp. on Robot Hum. Interact. Commun. Human-Robot Co-Existence: Adapt. Interfaces Syst. for Dly. Life, Ther. Assist. Socially Engaging Interactions 924-929 (2014). DOI 10.1109/ROMAN.2014.6926371.

112. Yun, S. et al. Engkey: Tele-education robot. In International Conference on Social Robotics, 142-152 (Springer, 2011).

113. Leite, I., Henriques, R., Martinho, C. \& Paiva, A. Sensors in the wild: Exploring electrodermal activity in child-robot interaction. In Proceedings of the 8th ACM/IEEE International Conference on Human-Robot Interaction, 41-48 (IEEE, 2013).

114. O’Shaughnessy, T. E., Lane, K. L., Gresham, F. M. \& Beebe-Frankenberger, M. E. Children Placed at Risk for Learning and Behavioral Difficulties: Implementing a School-Wide System of Early Identification and Intervention. Remedial Special Educ. 24, 27-35 (2003). DOI 10.1177/074193250302400103. 
115. Hackman, D. a., Farah, M. J. \& Meaney, M. J. Socioeconomic status and the brain: mechanistic insights from human and animal research. Nat. Rev. Neurosci. 11, 651-659 (2010). DOI 10.1038/nrn2897.

116. Noble, K. G., McCandliss, B. D. \& Farah, M. J. Socioeconomic gradients predict individual differences in neurocognitive abilities. Dev. Sci. 10, 464-480 (2007). DOI 10.1111/j.1467-7687.2007.00600.x. 